\title{
Endosurgery Approach in a Dog with Thoracoabdominal Injury
}

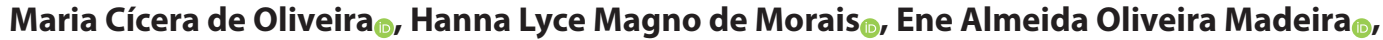 \\ Gabriela Melo Alves dos Santos, Thiago da Silva Cardoso ${ }_{\odot}$, Francisco Décio de Oliveira Monteiro, \\ Carolina Franchi João•\& Pedro Paulo Maia Teixeira
}

\begin{abstract}
Background: Chest trauma is one of the main thoracic injuries in dogs and cats, reaching a high morbidity and mortality. The tissue damage, in thoracic trauma, can be underappreciated by visual exam and traditional radiography. The thoracoscopy can provide information for a precise definitive diagnosis, by this technique bleeding or air leakage can be identified and corrected immediately and the diaphragm can be completely evaluated. The aim of this work was to describe the thoracoscopic approach in a case of diaphragmatic perforation caused by penetrating trauma in a dog.

Case: A 6-year-old male dog mixed-breed dog, weighing $14 \mathrm{~kg}$ with thorax perforation was presented to the Veterinary Hospital. Clinical examination of the animal revealed the following: pale mucous membranes, moderate dyspnea, open pneumothorax, abdominal distension, heart rate of 108 beats per minute and respiratory rate of 64 breaths per minute. Physical examination confirmed a $3 \mathrm{~cm}$ perforation hemorrhagic lesion in the left ninth intercostal space. As an emergency treatment, oxygen therapy, tramadol hydrochloride [Cronidor ${ }^{\circledR} 2 \%, 4 \mathrm{mg} / \mathrm{kg}$, i.v, TID], tranexamic acid [Transamin ${ }^{\circledR}$ $25 \mathrm{mg} / \mathrm{kg}$, i.v, TID], ceftriaxone [Rocefin ${ }^{\circledR} 50 \mathrm{mg} / \mathrm{kg}$, i.v, BID] and fluid therapy with lactated Ringer's solution were administered. The hair was removed, and then, wound cleaning and obliteration of the wall injury with sterile gauze was performed. After the emergency stabilization, the animal was anesthetized, followed by preventive thoracocentesis by an approach close to thoracic perforation and thoracoscopy without pneumoperitonea through this thoracic perforation with 0 -degree rigid endoscope. About $100 \mathrm{~mL}$ of blood and air was drained and diagnosed perforation in the diaphragm and pulmonary atelectasis in the caudal and left cranial lobes. the edges of the incisional wound were debrided, and the closure of thoracic incision was performed usual way. After that, the air was removed by a catheter and syringe system. A flexible plastic tube was inserted through the chest wall and into the pleural space for drainage every $2 \mathrm{~h}$ for $24 \mathrm{~h}$. There were no intercurrences during the first $24 \mathrm{~h}$ after the surgical procedure. The patient was discharged $48 \mathrm{~h}$ after the surgery. Cephalexin [ $75 \mathrm{mg}, 30 \mathrm{mg} / \mathrm{kg}$, v.o, TID, during 5 days), Ketoprofen [20 mg, $2 \mathrm{mg} / \mathrm{kg}$, v.o, SID, during 5 days], Tramadol Hydrochloride [50 mg, $4 \mathrm{mg} / \mathrm{kg}$, v.o, SID, during 2 days] and Rifamycin spray at the wound site was prescribed. Ten days after surgery, the patient returned to the hospital for suture removal and reassessment.

Discussion: The prognosis of chest perforation depends on the severity and number of internal and external thoracic lesions, as well as cardiovascular status at the time of initial patient care. In cases of penetrating chest trauma, it is essential to thoroughly examine the thoracic cavity for bleeding, tissue tears, and diaphragm perforation. The use of the endoscope allowed for a more detailed exploration of the chest without the need to increase the incision. When the diaphragm lesion was found, it was also possible to perform the abdominal examination by videoendoscopy, through this perforation. Laparotomy and thoracotomy cause postoperative pain and discomfort, in addition to increasing recovery time, however, even with trauma, not performing a larger incision favored the recovery of this patient, without any intercurrence in the first $24 \mathrm{~h}$ after the procedure. In conclusion, the endoscopic approach was efficient for diagnosis, avoiding greater trauma and contributing to a better clinical recovery of the patient.
\end{abstract}

Keywords: dog, chest trauma, minimally invasive surgery, thoracocentesis, thoracoscopy.

DOI: $10.22456 / 1679-9216.116907$ 


\section{INTRODUCTION}

Chest trauma is one of the main thoracic injuries in dogs and cats, reaching a high morbidity and mortality rate due to lesions involving pulmonary parenchyma, pleural space, large vessels, diaphragm or myocardium [5,13]. Cardiorespiratory arrest associated with chest trauma can interfere with patient survival in the pre- and perioperative period [8].

In thoracic trauma, organs of the respiratory and cardiovascular systems are priorities in treatment due to complications that can be fatal [10]. Any injury can lead to pulmonary complications with consequent decrease in the oxygen partial pressure $\left(\mathrm{PaO}_{2}\right)$ and peripheral arterial saturation $\left(\mathrm{SpO}_{2}\right)$, so it is very important to perform immediate oxygen ventilation in order to avoid eventual decompensation of the patient's clinical condition $[6,11]$.

The tissue damage, in thoracic trauma, can be underappreciated by visual exam and traditional radiography [10]. The thoracoscopy is a minimally invasive technique for visualizing the internal thoracic cavity, which can provide information for a precise definitive diagnosis [3]. By this technique, bleeding or air leakage can be identified and corrected immediately, moreover, the diaphragm can be completely evaluated, and if a diaphragmatic hernia is found, it can be repaired [4].

The aim of this work was to describe the thoracoscopic approach in a case of diaphragmatic perforation caused by penetrating trauma in a dog.

\section{CASE}

A 6-year-old male dog mixed-breed dog, weighing $14 \mathrm{~kg}$ was presented to the Veterinary Hospital of Pará Federal University for thorax perforation. The owner reported that the animal would have escaped at night and returned in the morning with a wound on the left side of the chest (Figure 1A).

Clinical examination of the animal revealed the following: pale mucous membranes, moderate dyspnea, open pneumothorax, abdominal distension, heart rate of 108 beats per minute and respiratory rate of 64 breaths per minute. Physical examination confirmed a $3 \mathrm{~cm}$ perforation hemorrhagic lesion in the left ninth intercostal space.

As an emergency treatment, oxygen therapy, tramadol hydrochloride ${ }^{1}$ [Cronidor $2 \%$ - $4 \mathrm{mg} / \mathrm{kg}$, i.v, TID], tranexamic acid ${ }^{2}$ [Transamin ${ }^{\circledR}-25 \mathrm{mg} / \mathrm{kg}$, i.v, TID], ceftriaxone ${ }^{3}$ [Rocefin ${ }^{\circledR}-50 \mathrm{mg} / \mathrm{kg}$, i.v, BID] and fluid therapy with lactated Ringer's solution were administered. The hair was removed, and then, wound cleaning and obliteration of the wall injury with sterile gauze was performed.

After the emergency stabilization, the animal was referred to the surgical center, being induced with propofol $^{4}$ [Propovet $^{\circledR}-6 \mathrm{mg} / \mathrm{kg}$, i.v) and intubated with an endotracheal tube. Isoflurane was used for anesthetic maintenance, with the patient undergoing assisted breathing. Aseptic preparation of the surgical field was performed with chlorhexidine and alcoholic solution of chlorhexidine, followed by preventive thoracocentesis, by an approach close to thoracic perforation. For that, a butterfly needle connected to a 3-way tap and a $20 \mathrm{~mL}$ syringe was used. About $100 \mathrm{~mL}$ of blood and air was drained.

Strict wound cleaning was performed. Then, through this thoracic perforation was inserted 0-degree rigid endoscope to explore the thoracic cavity (Figure 1B). In this way, thoracoscopy was performed. We detected perforation in the diaphragm and pulmonary atelectasis in the caudal and left cranial lobes (Figure 1C). Other thoracic structures were intact. We performed

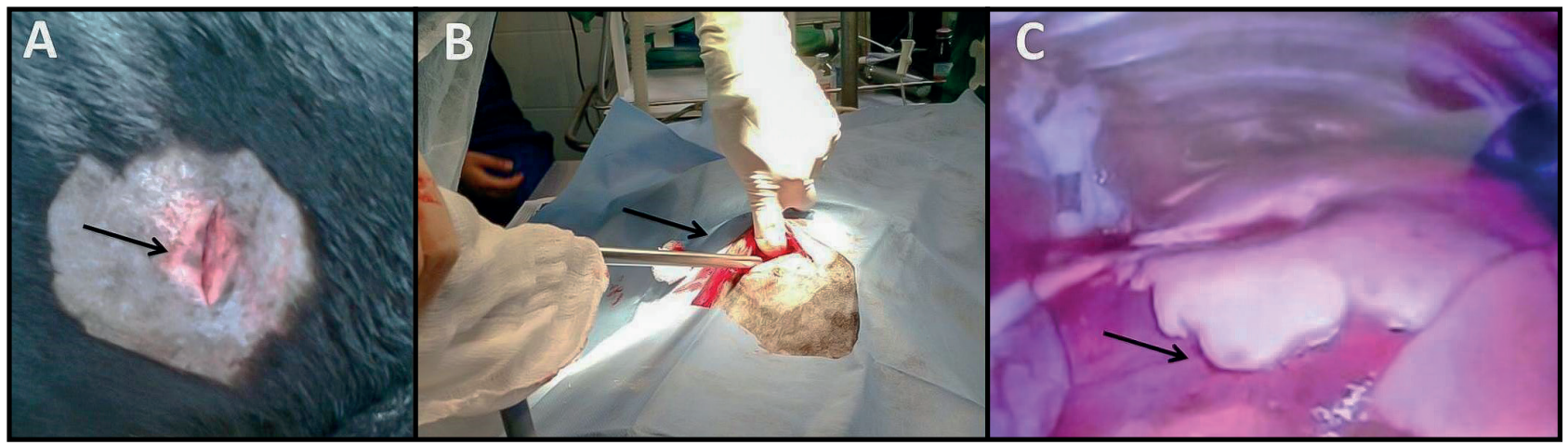

Figure 1. Thoraoscopy for open chest injury in dogs. A- Thoracoabdominal Injury. B- Thoracoscopy with rigid endoscopy. C- Perforation in the diaphragm and pulmonary atelectasis in the caudal and left cranial lobes. 
video-assisted thoracoscopy without pneumoperitoneum through the diaphragmatic injury caused by the perforation, visualizing the abdominal cavity.

The diaphragmatic lesion was repaired with a simple interrupted suture pattern, using nylon 2-0, through endoscopic visualization through the penetrating trauma hole, visualized from the thoracic cavity. Then, the edges of the incisional wound were debrided, and the closure of thoracic incision was performed usual way. After that, the air was removed by a catheter and syringe system. However, a flexible plastic tube was inserted through the chest wall and into the pleural space for drainage every $2 \mathrm{~h}$ for $24 \mathrm{~h}$.

There were no intercurrences during the first $24 \mathrm{~h}$ after the surgical procedure. The patient was discharged $48 \mathrm{~h}$ after the surgery. Rest and use of Elizabethan necklace were recommended during the recovery period. Cephalexin ${ }^{6}$ [Petsporin $^{\circledR}-75 \mathrm{mg}, 30 \mathrm{mg} / \mathrm{kg}$, v.o, TID, during 5 days], Ketoprofen ${ }^{7}$ [Kenovet ${ }^{\circledR}-20 \mathrm{mg}$, $2 \mathrm{mg} / \mathrm{kg}$, v.o, SID, during 5 days], Tramadol Hydrochloride $^{8}$ [Tramvetol ${ }^{\circledR}-50 \mathrm{mg}, 4 \mathrm{mg} / \mathrm{kg}$, v.o, SID, during 2 days] and Rifamycin spray ${ }^{9}$ Rifotrat $^{\circledR}-20 \mathrm{mg} / \mathrm{mL}$ ] at the wound site were prescribed. Ten days after surgery, the patient returned to the hospital for suture removal and reassessment. No sequelae were observed.

\section{DISCUSSION}

The patient presented some classic clinical signs of chest trauma such as pneumothorax, dyspnea, pale mucous membranes and abdominal distension. However, depending on the patient's cardiovascular condition, other signs such as cyanosis, tachycardia, hypotension or hypertension may occur in cases of thoracic perforation [8]. The dog presented moderate dyspnea, which was controlled during the emergency treatment, through oxygen therapy. The prognosis of chest perforation depends on the severity and number of internal and external thoracic lesions, as well as cardiovascular status at the time of initial patient care $[8,10]$.
In the present case, the patient had open pneumothorax, and this air in the pleural space may decrease negative pressure, resulting in atelectasis, consequently respiratory difficulty, severe hypoxemia, decreased venous return, hemodynamic instability, and may lead to death of the animal [10]. At the time of thoracoscopy, pulmonary atelectasis was observed in the caudal lobe and left cranial lobe, but no other severe complications [3]. In cases of penetrating chest trauma, it is essential to thoroughly examine the thoracic cavity for bleeding, tissue tears, and diaphragm perforation, which was observed in this animal $[2,10]$.

The use of the endoscope allowed for a more detailed exploration of the chest without the need to increase the incision [3]. When the diaphragm lesion was found, it was also possible to perform the abdominal examination by videoendoscopy, through this perforation $[1,7]$. Laparotomy and thoracotomy cause postoperative pain and discomfort, in addition to increasing recovery time, however, even with trauma, not performing a larger incision favored the recovery of this patient, without any intercurrence in the first $24 \mathrm{~h}$ after the procedure $[9,12]$.

In conclusion, the endoscopic approach was efficient for diagnosis, avoiding greater trauma and contributing to a better clinical recovery of the patient.

\section{MANUFACTURERS}

${ }^{1}$ União Química Farmacêutica Nacional S.A. São Paulo, SP, Brazil.

${ }^{2}$ Zydus Brasil. Rio de Janeiro, RJ, Brazil.

${ }^{3}$ Produtos Roche Químicos e Farmacêuticos S.A. Rio de Janeiro, RJ, Brazil.

${ }^{4}$ Ouro Fino Saúde Animal. Cajamar, SP, Brazil.

${ }^{5}$ Shalon Medical. São Luís de Montes Belos, GO, Brazil.

${ }^{6}$ Mundo Animal. Pindamonhangaba, SP, Brazil.

${ }^{7}$ Syntec do Brasil. Barueri, SP, Brazil.

${ }^{8}$ Virbac do Brasil Ind. Com. Ltda. Vila Leopoldina, SP, Brazil.

${ }^{9}$ Natulab Laboratório S.A. Santo Antônio de Jesus, BA, Brazil.

Acknowledgements. We would like thank FAPESP, CAPES, $\mathrm{CNPq}$ and PROPESP/UFPA for fomenting the research.

Declaration of interest. The authors declare no conflicts of interest. The authors are the only responsible for the content and writing of this case.

\section{REFERENCES}

1 Balsa I. \& Culp W. 2019. Use of Minimally Invasive Surgery in the Diagnosis and Treatment of Cancer in Dogs and Cats. Veterinary Science. 6(1): 33. DOI:10.3390/vetsci6010033.

2 Bhoite R., Preethi K., Chanakya T., Karunya G. \& Muralidhar D. 2021. Traumatic pneumothorax in golden retriever dog: A case report. Journal of Entomology and Zoology Studies. 9(2): 690-692. DOI: 10.22271/j.ento.2021. v9.i2j.8550. 
3 Case J.B. 2016. Advances in Video-Assisted Thoracic Surgery, Thoracoscopy. Veterinary Clinics: Small Animal Practice. 46(1): 147-169. doi: 10.1016/j.cvsm.2015.07.005.

4 Feranti J.P.S., Oliveira M.T., Hartmann H.F., Corrêa D.L.F., Pinto Filho S.T.L., Linhares M.T., Chaves R.O., Silva M.A.M. \& Brun M.V. 2016. Laparoscopic diaphragmatic hernioplasty in a dog. Brazilian Journal of Veterinary Research and Animal Science. 53(1): 103-106. DOI: 10.11606/issn.1678-4456.v53i1p103-106.

5 Intarapanich N.P., McCobb E.C., Reisman R.W., Rozanski E.A. \& Intarapanich P.P. 2016. Characterization and Comparison of Injuries Caused by Accidental and Non-accidental Blunt Force Trauma in Dogs and Cats. Journal of Forensic Sciences. 61(4): 993-999. DOI: 10.1111/1556-4029.13074.

6 Kirberger R.M., Leisewitz A.L., Rautenbach Y., Lim C.K., Stander N., Cassel N., Arnot L., DeClercq M. \& Burchell Richard. 2019. Association between computed tomographic thoracic injury scores and blood gas and acid-base balance in dogs with blunt thoracic trauma. Journal of Veterinary Emergency and Critical Care. 29(4): 373-384. doi: $10.1111 /$ vec. 12863 .

7 Kovak J.R., Ludwig L.L., Bergman P.J., Baer K.E. \& Noone K.E. 2002. Use of thoracoscopy to determine the etiology of pleural effusion in dogs and cats: 18 cases (1998-2001). Journal of the American Veterinary Medical Association. 221(7): 990-994. doi: 10.2460/javma.2002.221.990.

8 Lux C.N., Culp W.T.N., Mellema M.S., Rosselli D.D., Schmiedt C.W., Singh A., Haynes A., Schoenrock E., Selmic L.E., Phillips H., Milovancev M., Mayhew P.D. \& Brown D.C. 2018. Perioperative mortality rate and risk factors for death in dogs undergoing surgery for treatment of thoracic trauma: 157 cases (1990-2014). Journal of the American Veterinary Medical Association. 252(9): 1097-1107.DOI: 10.2460/javma.252.9.1097.

9 Peláez M.J. \& Jolliffe C. 2012. Thoracoscopic foreign body removal and right middle lung lobectomy to treat pyothorax in a dog. Journal of Small Animal Practice. 53(4): 240-244. DOI: 10.1111/j.1748-5827.2011.01175.x.

10 Peterson N.W., Buote N.J. \& Barr J.W. 2015. The impact of surgical timing and intervention on outcome in traumatized dogs and cats. Journal of Veterinary Emergency and Critical Care. 25(1): 63-75. DOI: 10.1111/vec.12279.

11 Rozanski E.A. 2015. Oxygenation and Ventilation. Veterinary Clinics: Small Animal Practice. 45(5): 931-940. DOI:10.1016/j.cvsm.2015.04.001.

12 Schmiedt C. 2009. Small Animal Exploratory Thoracoscopy. Veterinary Clinics: Small Animal Practice. 39(5): 953964. DOI:10.1016/j.cvsm.2009.05.007.

13 Zitz J., Rozanski E., Penninck D. \& Berg J. 2007. Managing dogs with thoracic impalement injuries: a review of nine cases. Veterinary Medicine. 102(5): 307-313. 